\title{
Clinical features and treatment of squamous cell carcinoma of the breast
}

This article was published in the following Dove Press journal:

OncoTargets and Therapy

27 May 2016

Number of times this article has been viewed

\author{
Ximei Zhang' \\ Baozhong Zhang' \\ Fenglin Zang ${ }^{2}$ \\ Lujun Zhao' \\ Zhiyong Yuan' \\ Ping Wang' \\ 'Department of Radiation Oncology, \\ 2Department of Pathology, Cancer \\ Institute and Hospital, Tianjin Medical \\ University, Tianjin, People's Republic \\ of China
}

Objectives: Data on breast squamous cell carcinoma (SCC) are rare. The aim of this study was to analyze the clinical characteristics and to explore the rational treatment of patients with breast SCC.

Patients and methods: We conducted a retrospective review of breast SCC cases treated at our center from 1966 to 2014 . The majority of these patients received primary surgery followed by adjuvant chemoradiotherapy, whilst four elderly patients had lumpectomy only.

Results: Patients with breast SCC were usually women, and large masses, large proportion of early stage disease, low levels of estrogen receptor expression, less frequent axillary lymph nodes involvement, and unfavorable prognosis were common. The 5-year overall survival and progression-free survival of all patients were $67.2 \%$ and $57.8 \%$, respectively. Axillary nodal involvement was a significant prognostic factor for survival.

Conclusion: The current results indicated that breast SCC is clinically aggressive and the outcomes were poor. Distant metastasis was the main failure pattern. New strategies will be needed because of the poor outcomes.

Keywords: breast metaplastic carcinoma, breast SCC, treatment, surgery, prognosis

\section{Introduction}

Squamous cell carcinoma (SCC) of the breast is exceedingly rare. The prevalence is estimated to be $<0.1 \%$ of all breast carcinomas. ${ }^{1,2}$ A literature review revealed that most of the studies were sporadic case reports or small case series. ${ }^{1-9}$ In addition, due to the lack of stringent pathological criteria, earlier reports always consisted of SCC tumors occurring with adenocarcinoma component or originating from the adjacent skin. Therefore, the clinical characteristics and treatment outcomes of patients with SCC of the breast have not been well defined. Furthermore, the treatment options for breast SCC have been based on extrapolation from the experience with breast infiltrating ductal carcinoma (IDC), so the optimal therapy for SCC of the breast has yet to be determined. To date, the prognosis and optimal treatment for SCC of the breast remain controversial. Although some authors believed that there were no significant differences between the prognosis of breast SCC and that of other breast malignancies, ${ }^{5,8,10,11}$ other reports suggested a poorer prognosis. ${ }^{6,7,12-14}$ To clearly identify the prognosis and treatment of this rare entity from our experience, we retrospectively studied the clinical characteristics and treatment outcomes of SCC of the breast treated in our hospital.

\section{Patients and methods}

Between 1966 and 2014, 37 consecutive patients with previously untreated SCC of the breast were reviewed at our institution. Since nine cases were diagnosed before the 
year 2000, our pathologist reviewed the histopathological slides and made the definitive diagnosis of SCC of the breast according to the criteria defined by Rosen: $\left.{ }^{15} 1\right)>90 \%$ of the area was SCC, 2) absence of skin involvement, and 3) absence of other primary SCC. Following reexamination, patients failing to meet the criteria were excluded, and the remaining 30 patients finally diagnosed as pure SCC of the breast comprised this study. The markers of estrogen receptor (ER), progesterone receptor (PR), and Her2/neu were also tested by immunohistochemistry according to the following criteria: $>10 \%$ of tumor cells with positive nuclear staining were regarded as ER/PR positive and $>10 \%$ of tumor cells with positive membranous staining were regarded as Her2/neu positive. In some patients, in the early stages of the study, hormone receptors were unavailable owing to the lack of enough tissue.

Information regarding demographic features, clinical findings, and treatment were reviewed from the medical records. Generally, all patients received cervical and abdominal ultrasonography and chest radiography, and if found to be in an advanced stage, isotope bone scan was suggested. In addition, contralateral mammography was applied to rule out the secondary breast carcinoma. This study was approved by the Institutional Review Board of Cancer Institute and Hospital, Tianjin Medical University, and all patients provided written informed consent in accordance with the Declaration of Helsinki.

\section{Treatment}

All patients received surgery as the primary treatment. Of them, five patients received breast conservative surgery (BCS) and 15 patients received mastectomy followed by chemotherapy and/or radiotherapy. The remaining four elderly patients (all $>80$ years old) had lumpectomy and refused any further therapy.

Cyclophosphamide-methotrexate-fluorouracil combination was the frequently used chemotherapy regimen more than 20 years ago, whereas taxane- or adriamycin-based chemotherapy regimens were used more frequently in the past 20 years. All the patients except the four elderly patients who had lumpectomy received adjuvant chemotherapy. Five patients also had neoadjuvant chemotherapy with the similar regimens. Six patients with T3/T4 stage disease or positive axillary lymph nodes were also instituted adjuvant radiotherapy. The radiotherapy field comprises chest wall and supraclavicular field, and the median radiation dose was 50 Gy (range 40-52), with a dose per fraction of 2 Gy.

\section{Statistical analysis}

Statistical analysis was performed using the statistical package for the social science (SPSS for Windows 15.0;
SPSS Inc., Chicago, IL, USA). Overall survival (OS) and progression-free survival (PFS) were estimated using the product limit Kaplan-Meier method. OS was calculated from the date of surgery to the time of death from any cause or until the last follow-up. PFS was calculated from the date of surgery to the time of disease progression, recurrence, or death. Treatment failure was defined as disease progression, recurrence, or metastasis. Survival differences between the groups were calculated using the log-rank test.

\section{Results \\ Patient characteristics}

Clinical characteristics of the patients are listed in Table 1. This study included one male patient and 29 female patients. The median age was 50 years (range: $28-87$ years), with four patients older than 80 years. The most common presenting symptom was palpable mass and a median tumor size of $3.1 \mathrm{~cm}$ (range: $1.1-15 \mathrm{~cm}$ ), with seven patients having a mass of $>5 \mathrm{~cm}$. Eleven $(11 / 30,36.7 \%)$ patients had axillary lymph node involvement, with two of them having more than four positive axillary nodes. The majority of patients $(25 / 30,83.3 \%)$ were in the early stage of tumor development (T1: $n=7$ and T2: $n=17$ ), according to the American Joint Committee on Cancer/Union for International Cancer Control (2010 edition) staging system for breast cancer. There were five patients with stage I disease, 18 patients with stage II disease, and seven patients with stage III disease. Of the patients with available receptor status, two patients $(2 / 19)$ were ER positive, one patient (1/18) was PR positive, and five patients $(5 / 15)$ were Her $2 /$ neu positive.

\section{Treatment outcomes}

With a median follow-up time of 55 months for living patients, the 5-year OS rate and PFS rate were $67.2 \%$ and $57.8 \%$, respectively, with the median OS and PFS not reached (Figure 1). At the final follow-up, 20 patients were alive with no evidence of disease, seven patients died from breast cancer, and the remaining three patients lived with disease.

Univariate analysis revealed that none of the following factors, including sex, age, primary location, tumor size, and overall stage, showed significant prognostic effect on OS. Interestingly, only axillary lymph node involvement was a significant prognostic factor for both OS and PFS (Table 2). The prognosis of patients who had axillary lymph node involvement was significantly inferior to those without. The 5-year OS and PFS rates were 100\% and 79.9\%, respectively, for patients without axillary lymph node involvement when compared with $31.7 \%$ and $31.8 \%$, respectively, for those 
Table I Clinical characteristics of patients with squamous cell carcinoma of the breast

\begin{tabular}{|c|c|c|}
\hline Characteristics & $\mathbf{n}$ & $\%$ \\
\hline \multicolumn{3}{|l|}{ Sex } \\
\hline Male & 1 & 3.3 \\
\hline Female & 29 & 96.7 \\
\hline \multicolumn{3}{|l|}{ Age (years) } \\
\hline Median (range) & $50(28-87)$ & \\
\hline$\leq 60$ & 21 & 70.0 \\
\hline$>60$ & 9 & 30.0 \\
\hline \multicolumn{3}{|l|}{ Location } \\
\hline Left & 14 & 46.7 \\
\hline Right & 16 & 53.3 \\
\hline Axillary lymph nodes & 11 & 36.7 \\
\hline \multicolumn{3}{|l|}{ Size $(\mathrm{cm}),(\mathrm{n}=27)$} \\
\hline Median (range) & $3.1(1.1-15)$ & \\
\hline$<5$ & 20 & \\
\hline$\geq 5$ & 7 & \\
\hline \multicolumn{3}{|l|}{ ER positivity } \\
\hline Positive & 2 & 6.5 \\
\hline Negative & 16 & 54.8 \\
\hline Not available & 12 & 38.7 \\
\hline \multicolumn{3}{|l|}{ PR positivity } \\
\hline Positive & 1 & 3.3 \\
\hline Negative & 16 & 54.8 \\
\hline Not available & 13 & 41.9 \\
\hline \multicolumn{3}{|l|}{ Her2 positivity } \\
\hline Positive & 5 & 16.1 \\
\hline Negative & 9 & 32.3 \\
\hline Not available & 16 & 51.6 \\
\hline \multicolumn{3}{|l|}{ Type of surgery } \\
\hline Mastectomy & 21 & 70.0 \\
\hline $\mathrm{BCS}$ & 5 & 16.7 \\
\hline Lumpectomy & 4 & 13.3 \\
\hline \multicolumn{3}{|l|}{ T stage } \\
\hline TI-2 & 24 & 80.0 \\
\hline T3-4 & 6 & 20.0 \\
\hline \multicolumn{3}{|l|}{$\mathrm{N}$ stage } \\
\hline No & 18 & 60.0 \\
\hline $\mathrm{NI}$ & 9 & 30.0 \\
\hline N2 & 3 & 10.0 \\
\hline \multicolumn{3}{|l|}{ Disease stage } \\
\hline 1 & 5 & 16.7 \\
\hline II & 18 & 60.0 \\
\hline III & 7 & 23.3 \\
\hline
\end{tabular}

Abbreviations: ER, estrogen receptor; PR, progesterone receptor; $B C S$, breast conservative surgery.

with axillary lymph node involvement (OS: $P=0.002$ and PFS: $P=0.039$; Figure 2).

\section{Patterns of failure}

Ten patients $(10 / 30,33.3 \%)$ had disease progression or developed recurrence. Median time to treatment failure from the surgery was 19.5 months. Of the patients with treatment failure, three patients had local regional recurrence, five patients had distant metastasis, and two patients had both

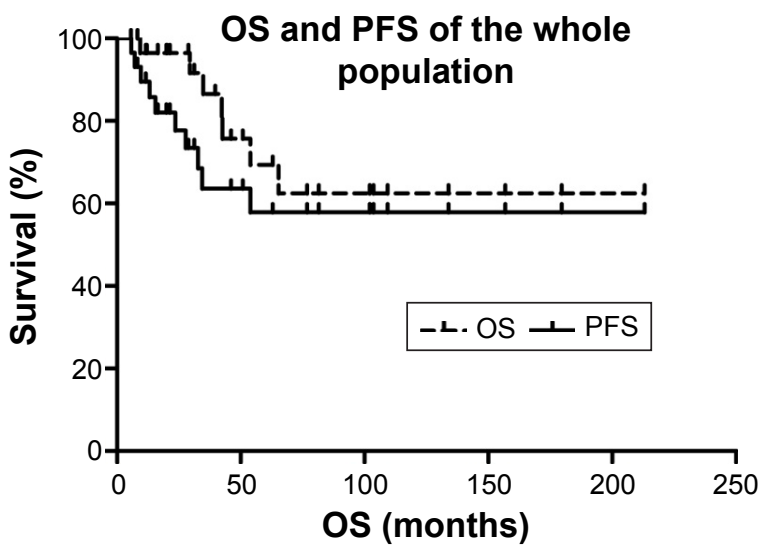

Figure I OS and PFS rates in 30 patients with breast squamous cell carcinoma. Abbreviations: OS, overall survival; PFS, progression-free survival.

local and distant metastases. There was no difference between radical and conservative surgery groups. Of the patients with relapsed disease, two patients with localized disease received radiotherapy, three patients with distant disease received chemotherapy, and the remaining five patients refused further therapy. The median survival of the patients with relapsed disease was only 6.0 months.

\section{Discussion}

Although the clinicopathological features of breast IDC have been well recognized, there are few data regarding the clinical behavior and treatment outcomes of breast SCC. This study

Table 2 Prognostic factors in patients with breast squamous cell carcinoma

\begin{tabular}{|c|c|c|c|c|}
\hline \multirow[t]{2}{*}{ Characteristics } & \multicolumn{2}{|c|}{ 5-year OS } & \multicolumn{2}{|c|}{ 5-year PFS } \\
\hline & $\%$ & $P$-value & $\%$ & $P$-value \\
\hline \multicolumn{5}{|l|}{ Age (years) } \\
\hline$<60$ & 60.6 & 0.322 & 48.2 & 0.211 \\
\hline$\geq 60$ & 87.5 & & 87.5 & \\
\hline \multicolumn{5}{|l|}{ Location } \\
\hline Left & 77.8 & 0.621 & 58.4 & 0.857 \\
\hline Right & 59.9 & & 57.0 & \\
\hline \multicolumn{5}{|c|}{ Axillary lymph nodes } \\
\hline Positive & 31.7 & 0.002 & 31.8 & 0.039 \\
\hline Negative & 87.5 & & 79.9 & \\
\hline \multicolumn{5}{|l|}{ Tumor size $(\mathrm{cm})$} \\
\hline$<5$ & 67.7 & 0.925 & 61.5 & 0.730 \\
\hline$\geq 5$ & 64.3 & & 66.7 & \\
\hline \multicolumn{5}{|l|}{ Surgery type } \\
\hline Mastectomy & 63.2 & 0.638 & 50.4 & \\
\hline $\mathrm{BCS}$ & 60.0 & & 60.0 & \\
\hline \multicolumn{5}{|l|}{ Disease stage } \\
\hline I & 50 & 0.572 & 75 & 0.377 \\
\hline II & 67.5 & & 57.3 & \\
\hline III & 51.4 & & 42.9 & \\
\hline
\end{tabular}

Abbreviations: OS, overall survival; PFS, disease free survival; BCS, breast conservative surgery. 

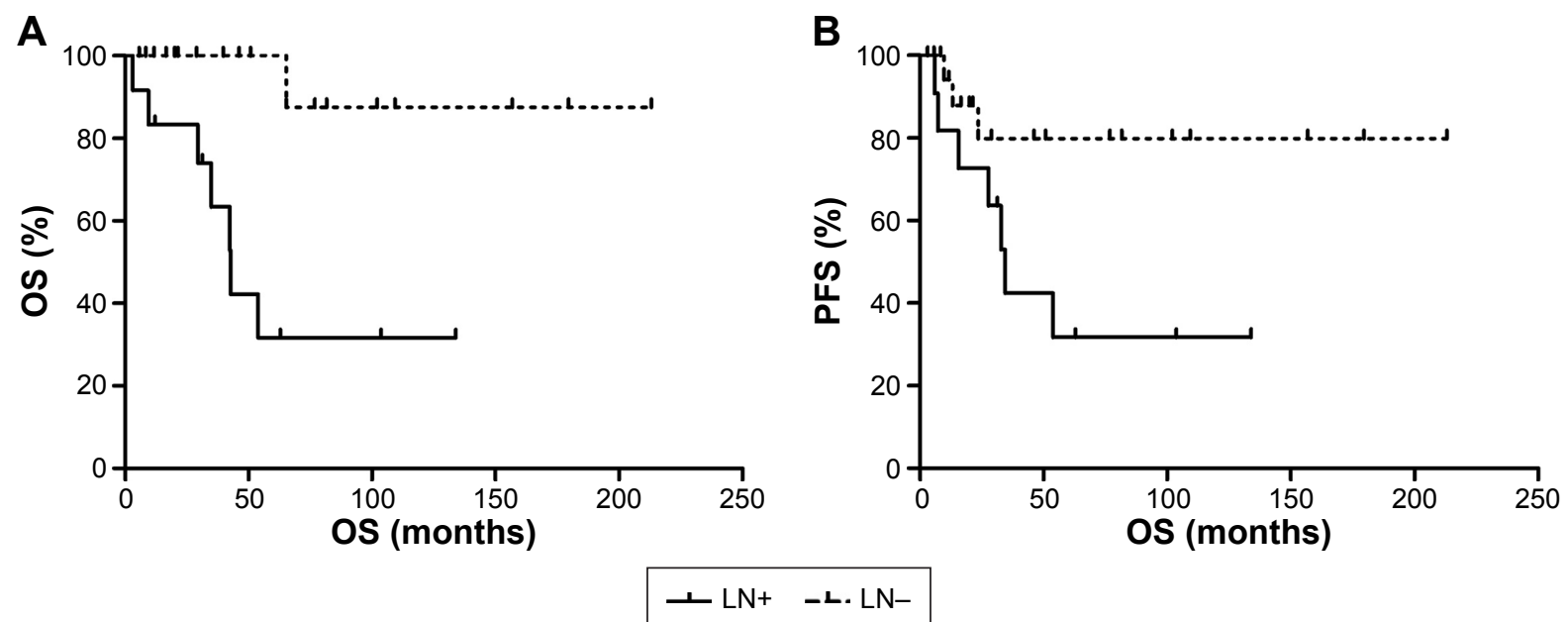

Figure 2 (A) OS and (B) PFS rates in 30 patients who had or did not have positive axillary lymph nodes. Abbreviations: LN, lymph node; OS, overall survival; PFS, progression-free survival.

provides the clinical features and treatment outcomes of a relatively large series of patients with breast SCC.

Most of the clinical features of SCC of the breast, such as large proportion of patients diagnosed in the early stage of disease, low levels of ER expression, and less frequent involvement of axillary lymph nodes, are in contrast to those of IDC. Although some of the abovementioned features are suggestive of a low-tumor burden, as indicated by a large proportion of patients with early stage disease and less frequent involvement of axillary lymph nodes, they still had an unfavorable prognosis, which is largely poorer than stage-adjusted IDC. The survival outcomes in this study are comparable with other studies, ${ }^{6,7,12-14,16}$ where the 5-year OS rate and PFS rate were $67.2 \%$ and $57.8 \%$, respectively. The OS rate is similar to that in the reports from Grabowski et al, ${ }^{12}$ Behranwala et al, ${ }^{7}$ and surveillance epidemiology and end results data ${ }^{13}$ but differs from the rates reported by Hennessy et $\mathrm{al}^{13}$ and Aparicio et al. ${ }^{6}$

Given the rarity of this tumor, most of the patients were treated similar to IDC considering that these malignancies share the same primary site. However, due to the invasiveness and poorer prognosis, mastectomy is frequently used as shown by a majority of the reports..$^{6-8,13,14}$ Most studies on SCC of the breast reported favorably on the administration of mastectomy instead of BCS. Whether or not BCS is a safe and effective treatment option for this rare entity is unknown. In this study, five patients received BCS, though the small series, at the final follow-up, and none had local regional recurrences. Therefore, we believe that BCS is a reasonable option as the treatment for SCC of the breast. Data from metaplastic breast cancers (MBCs) also demonstrate that $\mathrm{BCS}$ is a choice for the treatment for patients with $\mathrm{MBC}$, and the survival was comparable between the two surgery types. ${ }^{17}$
This, combined with our experience, suggests that BCS is not contraindicated in the treatment of SCC of the breast.

In addition, none of the studies have addressed the role of more conservative surgery such as lumpectomy for the treatment of SCC of the breast. Our study had proved that lumpectomy was safe for the cohort of very elderly patients who have been always associated with other comorbidities. In this study, the four elderly patients had at least one comorbidity. Therefore, lumpectomy was used, and given the relatively long follow-up period, the survival was favorable, which proved that lumpectomy was safe and effective. This is consistent with the observations that tumors always grow more slowly in old people. ${ }^{18,19}$ This might be explained by either physical factors or immunological factors.

Of interest, neoadjuvant chemotherapy was undertaken in five patients; however, no response was observed, and tumor progressed in one patient. The same phenomenon was seen in Hennessy et al's ${ }^{13}$ and Nayak et al's ${ }^{14}$ studies. This, to some extent, reveals the chemoresistance of SCC of the breast, which is different from SCC originating from head and neck regions with a complete response rate as high as $80 \% .{ }^{16}$ Poor response to chemotherapy suggested that neoadjuvant chemotherapy is not applicable in advanced SCC of the breast. In addition, most of the histopathological and immunohistochemical analyses of MBCs suggested that they have a basal-like phenotype..$^{20,21}$ However, as a subtype of MBCs, response to chemotherapy for SCCs of the breast is extremely poor, which is different from basal-like infiltrating carcinoma. ${ }^{22}$ Chemoresistance and the triple negativity of SCC of the breast preclude the conventional chemotherapy, targeted therapy, and neoadjuvant therapy. Innovative chemotherapy regimens need to be explored in the future. 
Patterns of failure in our study were mainly due to distant metastasis, and seven of the ten patients experienced distant metastasis. Our results were consistent with Aparicio et al's ${ }^{6}$ and Behranwala et al's ${ }^{7}$ reports. On the contrary, in Hennessy's study, ${ }^{13}$ which included a relatively large population of patients with SCC of the breast, $40 \%$ patients suffered from local regional relapse. The author stated that the reasons for the high local regional relapse were not clear. In this study, median survival from treatment failure was only 6 months, suggesting a poorer prognosis after relapse and calling for newer chemotherapy regimens.

\section{Conclusion}

SCC of the breast is clinically rare and aggressive. Treatment outcomes were poor after primary surgery and adjuvant chemoradiotherapy. Distant metastasis was the main failure pattern. As a result, the addition of newer chemotherapy regimens and target therapy into the innovative multimodality therapy might improve the patients' outcomes.

\section{Disclosure}

The authors report no conflicts of interest in this work.

\section{References}

1. Wrightson WR, Edwards MJ, McMasters KM. Primary squamous cell carcinoma of the breast presenting as a breast abscess. Am Surg. 1999; 65(12):1153-1155.

2. Menes T, Schachter J, Morgenstern S, Fenig E, Lurie H, Gutman H. Primary squamous cell carcinoma (SqCC) of the breast. Am J Clin Oncol. 2003;26(6):571-573.

3. Moisidis E, Ahmed S, Carmalt H, Gillett D. Primary squamous cell carcinoma of the breast. ANZ J Surg. 2002;72(1):65-67.

4. Sheen-Chen S, Chen Y, Chou F, Eng H. Primary squamous cell carcinoma of the breast. South Med J. 1992;85(2):207-209.

5. Weigel RJ, Ikeda DM, Nowels KW. Primary squamous cell carcinoma of the breast. South Med J. 1996;89(5):511-515.

6. Aparicio I, Martínez A, Hernández G, Hardisson D, De Santiago J. Squamous cell carcinoma of the breast. Eur J Obstet Gynecol Reprod Biol. 2008;137(2):222-226.
7. Behranwala KA, Nasiri N, Abdullah N, Trott PA, Gui GP. Squamous cell carcinoma of the breast: clinico-pathologic implications and outcome. Eur J Surg Oncol. 2003;29(4):386-389.

8. Cardoso F, Leal C, Meira A, et al. Squamous cell carcinoma of the breast. Breast. 2000;9(6):315-319.

9. Stevenson JT, Graham DJ, Khiyami A, Mansour EG. Squamous cell carcinoma of the breast: a clinical approach. Ann Surg Oncol. 1996;3(4): 367-374.

10. Campana YJ, Vilcoq JR, Vielh P, et al. Carcinoma epidermoide primitif du sein. Etude clinique, histopathologique et prognostiquede 14 patientes. [Primary epidermoid carcinoma of the breast. Clinical, histopathologic and prognostic study of 14 patients]. Bull Cancer. 1992; 79:675-679.

11. Wargotz ES, Norris HJ. Metaplastic carcinomas of the breast. Cancer. 1990;65(2):272-276.

12. Grabowski J, Saltzstein SL, Sadler G, Blair S. Squamous cell carcinoma of the breast: a review of 177 cases. Am Surg. 2009;75(10):914-917.

13. Hennessy BT, Krishnamurthy S, Giordano S, et al. Squamous cell carcinoma of the breast. J Clin Oncol. 2005;23(31):7827-7835.

14. Nayak A, Wu Y, Gilcrease MZ. Primary squamous cell carcinoma of the breast: predictors of locoregional recurrence and overall survival. Am J Surg Pathol. 2013;37(6):867-873.

15. Rosen PR, editor. Chapter 19. Rosen's Breast Pathology. Philadelphia, PA: Lippincott Williams \& Wilkins; 2001:455-461.

16. Lorch JH, Goloubeva O, Haddad RI, et al. Induction chemotherapy with cisplatin and fluorouracil alone or in combination with docetaxel in locally advanced squamous cell cancer of the head and neck: longterm results of the TAX 324 randomised phase 3 trial. Lancet Oncol. 2011;12(2):153-159.

17. Dave G, Cosmatos H, Do T, Lodin K, Varshney D. Metaplastic carcinoma of the breast: a retrospective review. Int J Radiat Oncol Biol Phys. 2006;64(3):771-775.

18. Ershler WB, Stewart JA, Hacker MP, Moore AL, Tindle BH. B16 murine melanoma and aging: slower growth and longer survival in old mice. J Natl Cancer Inst. 1984;72(1):161-164.

19. Auerbach R, Kubai L, Sidky Y. Angiogenesis induction by tumors, embryonic tissues, and lymphocytes. Cancer Res. 1976;36(9 PT 2): 3435-3440.

20. Weigelt B, Kreike B, Reis-Filho JS. Metaplastic breast carcinomas are basal-like breast cancers: a genomic profiling analysis. Breast Cancer Res Treat. 2009;117(2):273-280.

21. Grenier J, Soria JC, Mathieu MC, et al. Differential immunohistochemical and biological profile of squamous cell carcinoma of the breast. Anticancer Res. 2007;27(1B):547-555.

22. Rouzier R, Perou CM, Symmans WF, et al. Breast cancer molecular subtypes respond differently to preoperative chemotherapy. Clin Cancer Res. 2005;11(16):5678-5685.
OncoTargets and Therapy

\section{Publish your work in this journal}

OncoTargets and Therapy is an international, peer-reviewed, open access journal focusing on the pathological basis of all cancers, potential targets for therapy and treatment protocols employed to improve the management of cancer patients. The journal also focuses on the impact of management programs and new therapeutic agents and protocols on

\section{Dovepress}

patient perspectives such as quality of life, adherence and satisfaction. The manuscript management system is completely online and includes a very quick and fair peer-review system, which is all easy to use. Visit http://www.dovepress.com/testimonials.php to read real quotes from published authors. 